INTERNATIONAL JOURNAL OF RESEARCHES IN BIOSCIENCES, AGRICULTURE AND TECHNOLOGY (C) VISHWASHANTI MULTIPURPOSE SOCIETY (Global Peace Multipurpose Society) R. No. MH-659/13(N) www.vmsindia.org

\title{
MICROWAVE DIELECTRIC AND THERMODYNAMIC PROPERTIES OF PYRIDINE AND ANILINE IN DIFFERENT NON POLAR LIQUIDS
}

\author{
N. S. Ramteke ${ }^{1}$, S. B. Gedam ${ }^{2}$, K. W. Masurkar ${ }^{1}$ and B. M. Suryavanshi ${ }^{3}$ \\ 1,Dr. Ambedkar College, Chandrapur (M.S.) (India) \\ 2,M. G. College Armori Dist- Gadchiroli - 441208 (M.S.) (India) \\ 3.Institute of Science, Nagpur (M.S.) (India) \\ bm_suryavanshi@yahoo.co.in
}

\begin{abstract}
:
Dielectric constant, dielectric loss of Pyridine and Aniline in dilute solutions in different non polar media, viz., cyclohexane, benzene and heptane at $10 \mathrm{GHz}$ and at three different temperatures have been determined. Dielectric data of the solutions have been analysed to determine microscopic relaxation times ( $\tau$ ) and dipole moments $(\mu)$ of the systems used. Temperature dependent relaxation times of the dilute solutions and coefficient of viscosities $(\eta)$ of the solvent are used in calculations of the Eyrings thermodynamic energy parameters for the activated state of the system.
\end{abstract}

Keywords: Dielectric constant, Loss, Relaxation time, Dipole moment, Thermodynamic parameters.

\section{Introduction:}

All organic polar molecules have asymmetric distribution of electric charge (positive nucleus and negative electrons) which on interaction with the microwave radiation displaces slightly and contributes to dielectric permittivity. Dielectric measurements of polar molecules in dilute solutions of non polar solvent in the microwave region are helpful to obtain information about the polar molecule ${ }^{1}$. Pyridine and aniline are benzene derivatives. Microwave absorption is the non quantal absorption process of the polar molecule in non polar medium in liquid state $^{3}$. The present investigations report the microscopic values of relaxation time $(\square)$, dipole moment $(\mu)$ and thermodynamic energy parameter ${ }^{3}$ of the systems in three different non polar media. The relaxation parameters of the systems are compared with respect to different solvent media.

\section{Experimental:}

The chemicals Pyridine, aniline and non polar heptanes and benzene of AR grade have been obtained commercially with a purity of 99\% specification and they are used without any further purification. Dilute solutions of polar liquids were prepared at a room temperature and used immediately for dielectric measurements. Dielectric constant $\left(\varepsilon^{\prime}\right)$ and loss $(\varepsilon$ ") have been determined at $\mathrm{x}$-band $(10 \mathrm{GHz})$, at different temperatures by using standing wave technique of Smyth ${ }^{5}$. The accuracy of the measurements for dielectric constant $\left(\varepsilon^{\prime}\right)$ and loss ( $(")$ was found to be within +_2\% and +_5\% respectively. Viscosities of the solvent at different temperatures have been determined by using calibrated Ostwald type viscometer. Relaxation time $(\tau)$ and dipole moment $(\mu)$ of the systems are determined by using the Gopala Krishna method ${ }^{6}$ and thermodynamic energy parameters by using the Eyring's equations ${ }^{3}$.

\section{Result and Discussion:}

The X-band microwave bench was used to measure the wavelength of the microwave radiation in liquid dielectric cell. The liquid sample was hold vertically in a liquid cell by supporting a thin mica sheet whose VSWR and attenuation were assumed negligible small. The liquid dielectric cell was attached at the end of microwave bench. The following (1 and 2) Smyth's equations ${ }^{4}$ are used to calculate dielectric constant, dielectric loss at microwave frequency.

$\varepsilon^{\prime}=\left(\frac{\lambda_{0}}{\lambda_{c}}\right)^{2}+\left(\frac{\lambda_{0}}{\lambda_{d}}\right)^{2}$.

$\varepsilon^{\prime \prime}=\frac{2}{\pi}\left(\frac{\lambda_{o}}{\lambda_{d}}\right)^{2} \cdot \frac{\lambda_{g}}{\lambda_{d}} \cdot \frac{d \rho}{d n}$.

Where,

$\lambda_{0}$ - Wavelength of microwave radiation.

$\lambda_{\mathrm{c}}-$ Cut off wavelength in the wave guide.

$\lambda_{d}$ - Wavelength of microwave radiation in liquid medium.

The procedure of measurement on X-band is describe elsewhere 4

A Gopala Krishna method 5 based on Debye molecular model, eq.(3) is used to determine a relaxation time( $\mathrm{\tau})$ eq.(4) and electric dipole moment $(\mu)$ from eq.(5).

$\left[\varepsilon^{*}-1 / \varepsilon^{\star}-2\right]=\left[\varepsilon_{\infty}-1\right] /\left[\varepsilon_{\infty}-2\right]+\left[4 \pi \eta \mu^{2} / 9 \mathrm{KT}\right][1 /(1+j \omega \tau) \ldots(3)$ 
Where,

$\varepsilon^{*}=\varepsilon^{\prime}-\mathrm{j} \varepsilon^{\prime \prime}$

$\tau=\frac{1}{2 \pi f}\left(\frac{d Y}{d X}\right)$

$\mu^{2}=\frac{9 k T M}{4 \pi N d_{0}}\left[1+\left(\frac{d Y}{d X}\right)^{2}\right] \frac{d X}{d W}$

Table-1 reports the values of relaxation time ( $\square$ ), dipole moment $(\mu)$ and thermodynamic energy parameters of the pyridine and aniline in three different non polar solvents, viz.., cyclohexane, benzene and heptane. Coefficent of viscosities of the three solvents at different temperatures are measured using Ubenhold viscometer also reported in the table. Relaxation time $\square=4.43$ $\mathrm{pS}$ is the larger relaxation time of pyridine in benzene at $25^{\circ} \mathrm{C}$, whereas it is smaller than aniline $(\square=4.50 \mathrm{pS})$ in benzene at $25{ }^{\circ} \mathrm{C}$. This may be due to the rotational hindrance of aniline in benzene medium.

TABLE-1: Viscosity, dielectric relaxation and thermodynamic properties of polar solute at different temperatures in different non polar solvent

\begin{tabular}{|c|c|c|c|c|c|c|c|c|c|}
\hline \multirow{2}{*}{$\begin{array}{l}\text { Polar solute, } \\
\text { solvent, } \\
\text { Temp. }\left({ }^{\circ} \mathrm{C}\right)\end{array}$} & \multirow{2}{*}{$\begin{array}{l}\text { Viscosity } \\
\square\end{array}$} & \multirow{2}{*}{$\begin{array}{l}\text { Relaxation } \\
\text { time } \\
\end{array}$} & \multirow{2}{*}{$\begin{array}{l}\begin{array}{l}\text { Dipole } \\
\text { moment }\end{array} \\
\mu \mathrm{D}\end{array}$} & \multicolumn{6}{|c|}{$\begin{array}{l}\text { Thermodynamic energy parameters } \\
\text { (kcal/mol degree) }\end{array}$} \\
\hline & & & & $\Delta \mathrm{H} \square$ & $\Delta \mathrm{F} \square$ & $\Delta \mathrm{S} \square *$ & $\Delta \mathrm{H} \square$ & $\Delta \mathrm{F} \square$ & $\Delta \mathrm{S} \square *$ \\
\hline \multicolumn{10}{|l|}{ A:Pyridine } \\
\hline 25 & 0.786 & 4.43 & 2.24 & 1.42 & 1.92 & -1.63 & 2.52 & 2.92 & -1.41 \\
\hline 30 & 0.719 & 4.35 & 2.24 & & 1.92 & -1.72 & 2.52 & 2.93 & -1.44 \\
\hline 35 & 0.672 & 4.45 & 2.25 & & 1.97 & -1.72 & 2.52 & 2.94 & -1.45 \\
\hline 40 & 0.612 & 3.56 & 2.25 & & 1.97 & -1.69 & 2.52 & 2.95 & -1.45 \\
\hline Heptane & & & & & & & & & \\
\hline 25 & 0.409 & 4.40 & 2.22 & 1.45 & 1.85 & -1.66 & 2.52 & 2.92 & -0.42 \\
\hline 30 & 0.400 & 4.35 & 2.22 & & 1.87 & -1.52 & & 2.93 & -0.42 \\
\hline 35 & 0.368 & 4.34 & 2.21 & & 1.89 & -1.52 & & 2.94 & -0.43 \\
\hline 40 & 0.341 & 4.50 & 2.22 & & 1.90 & -1.49 & & 2.95 & -0.50 \\
\hline Benzene & & & & & & & & & \\
\hline 25 & 0.62 & 1.50 & 2.23 & 1.42 & 1.92 & -1.62 & 2.63 & 2.91 & -0.94 \\
\hline 30 & 0.58 & 4.25 & 2.12 & & 1.92 & -1.66 & & 2.92 & -0.95 \\
\hline 35 & 0.56 & 4.10 & 2.10 & & 1.94 & -1.62 & & 2.94 & -0.95 \\
\hline 40 & 0.54 & 3.92 & 2.11 & & 1.98 & -1.62 & & 2.95 & -0.99 \\
\hline \multicolumn{10}{|l|}{ B: Aniline } \\
\hline $\begin{array}{l}\text { Cyclohexane } \\
25\end{array}$ & & & & 142 & & & 52 & & \\
\hline $\begin{array}{l}25 \\
30\end{array}$ & 0.7 & $\begin{array}{l}4.02 \\
4.31\end{array}$ & $\begin{array}{l}1.42 \\
1.62\end{array}$ & 1.42 & $\begin{array}{l}1.71 \\
1.76\end{array}$ & $\begin{array}{l}-1.44 \\
-1.46\end{array}$ & 2.02 & $\begin{array}{l}2.92 \\
2.93\end{array}$ & $\begin{array}{l}-1.41 \\
-1.44\end{array}$ \\
\hline 35 & 0.672 & 4.3 & 1.55 & & 1.75 & -1.46 & & 2.94 & -1.45 \\
\hline 40 & 0.612 & 4.24 & 1.52 & & 1.73 & -1.49 & & 2.95 & -1.45 \\
\hline Heptane & & & & & & & & & \\
\hline 25 & 0.409 & 4.40 & 1.53 & 1.50 & 1.77 & -1.60 & 2.52 & 2.92 & -0.42 \\
\hline 30 & 0.400 & 4.35 & 1.53 & & 1.88 & -1.74 & & 2.93 & -0.42 \\
\hline 35 & 0.368 & 4.34 & 1.53 & & 1.89 & -1.62 & & 2.94 & -0.45 \\
\hline 40 & 0.341 & 3.50 & 1.52 & & 1.88 & -1.49 & & 2.95 & -0.43 \\
\hline \multicolumn{10}{|l|}{ Benzene } \\
\hline 25 & 0.62 & 4.50 & 1.23 & 2.77 & 1.22 & -0.87 & 2.63 & 2.92 & -0.92 \\
\hline 30 & 0.58 & 4.25 & 1.53 & & 1.24 & -0.87 & & 2.92 & -0.95 \\
\hline 35 & 0.56 & 4.10 & 1.53 & & 1.30 & -0.77 & & 2.94 & -0.95 \\
\hline 40 & 0.54 & 3.92 & 1.53 & & 1.35 & -0.61 & & 2.94 & -0.99 \\
\hline
\end{tabular}

* Units are in $\mathrm{cal} / \mathrm{mol} /$ degree

\section{Conclusion:}

The large values of relaxation time and free energy of activation pyridine in benzene solution indicate that there may be between pyridine and benzene molecule. Comparing relaxation parameters of aniline in benzene with corresponding values in other two solvents, it is concluded that there is a weak association between aniline and benzene medium. 


\section{Acknowledgement:}

Author (NSR) thankful to Dr.

Dhahegaonker, Principal, Dr Ambedkar College Chandrapur for encouragement. The author BMS) thanks to UGC WR Pune for grant of minor research project (No.F.4)-10/2003.

\section{References:}

1. N. E. Hill, W. E. Vaughan, A. H. Price and M. Davice, Dielectric Properties and Molecular Behaviour, Van Nostrand Reinhold Co. London (1969).

2. B. M. Suryavanshi and S. C. Mehrotra, Indian J. Pure Appl. Phy. 29, 482 (1991).
4. K. V. Gopala Krishna, Trans. Farad. Soc., 53, 767, (1957).

3. E. S. Glaston, K. J. Laidier and H. Eyring, Theory of Rate Process, McGraw Hill Book Co., New York p. 548 (1941)

5. W. M. Hestpm (Jr), A. D. Franklin, E. J. Heennelly and C. P. Smyth, J. Am. Chem. Soc., 72, 3443 (1950).

4. A. L. McClellan, Tables of Electric Dipole Moments, W. H. Freeman \& Co. London (1963).

5. F. H. Branin (Jr.) and C. P. Smyth, J. Chem. Phys., 20, 11212 (1952). 